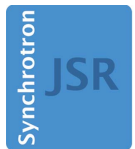

JOURNAL OF SYNCHROTRON RADIATION

ISSN 1600-5775

Keywords: microcrystallography; macromolecular crystallography; MD3Up high-precision multi-axis diffractometer.
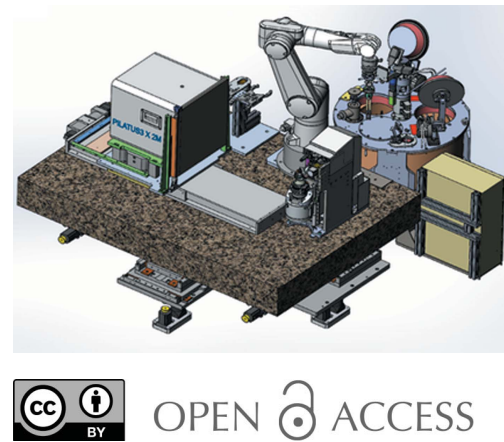

Published under a CC BY 4.0 licence

\section{ID23-2: an automated and high-performance microfocus beamline for macromolecular crystallography at the ESRF. Corrigendum}

\author{
Max Nanao, ${ }^{\text {a* }}$ Shibom Basu, ${ }^{\text {b }}$ Ulrich Zander, ${ }^{\text {b }}$ Thierry Giraud, ${ }^{\text {a }}$ John Surr, ${ }^{\text {a }}$ \\ Matias Guijarro, ${ }^{a}$ Mario Lentini, ${ }^{a}$ Franck Felisaz, ${ }^{\text {b }}$ Jeremy Sinoir, ${ }^{b}$ \\ Christian Morawe, ${ }^{a}$ Amparo Vivo, ${ }^{a}$ Antonia Beteva, ${ }^{a}$ Marcus Oscarsson, ${ }^{a}$ \\ Hugo Caserotto, ${ }^{a}$ Fabien Dobias, ${ }^{a}$ David Flot, ${ }^{a}$ Didier Nurizzo, ${ }^{a}$ Jonathan Gigmes, ${ }^{a}$

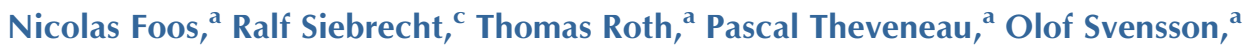 \\ Gergely Papp, ${ }^{a}$ Bernard Lavault, ${ }^{\text {c }}$ Florent Cipriani, ${ }^{b}$ Ray Barrett, ${ }^{a}$ Carole Clavel $^{\text {a }}$ \\ and Gordon Leonard ${ }^{\mathrm{a}}$
}

${ }^{a}$ European Synchrotron Radiation Facility, 71 Avenue des Martyrs, F-38000 Grenoble, France, ${ }^{\mathbf{b} E u r o p e a n}$ Molecular Biology Laboratory, 71 Avenue des Martyrs, 38042 Grenoble, France, and ' ARINAX, 365 Rue de Corporat, 38430 Moirans, France. *Correspondence e-mail: max.nanao@esrf.fr

A revised version of Table 2 of Nanao et al. [J. Synchrotron Rad. (2022). 29, 581590] is provided.

Some of the values reported in Table 2 of Nanao et al. (2022) were found to be incorrect. The full correct table is shown below.

Table 2

Data collection and refinement statistics.

Statistics for the highest-resolution shell are shown in parentheses. For the MeshAndCollect data, the average cell edge and range are provided. A refinement was not performed for these data.

\begin{tabular}{lll}
\hline & $\begin{array}{l}\text { Cubic insulin } \\
\text { helical }\end{array}$ & $\begin{array}{l}\text { Cubic insulin } \\
\text { MeshAndCollect }\end{array}$ \\
\hline Wavelength $(\AA)$ & 0.873 & 0.873 \\
No. of crystals & 1 & 142 \\
Resolution range $(\AA)$ & $39.28-1.203$ & $32.07-1.750$ \\
& $(1.246-1.203)$ & $(1.80-1.75)$ \\
Space group & $I 2.3$ & $I 2{ }_{1} 3$ \\
Unit cell & & \\
$\quad a, b, c(\AA)$ & 78.50 & $78.47(78.27-78.73)$ \\
$\quad \alpha, \beta, \gamma\left({ }^{\circ}\right)$ & 90 & 90 \\
Total reflections & $2269388(146102)$ & $1257717(95649)$ \\
Unique reflections & $25126(2395)$ & $15814(1184)$ \\
Multiplicity & $90.3(58.7)$ & $79.53(80.78)$ \\
Completeness $(\%)$ & $99.45(95.30)$ & $100(99.7)$ \\
$\langle I / \sigma(I)\rangle$ & $30.66(1.26)$ & $25.48(1.36)$ \\
Wilson $B$ factor & 17.03 & 13.18 \\
$R_{\text {meas }}$ & $0.106(2.697)$ & $0.155(4.143)$ \\
CC ${ }_{1 / 2}$ & $1(0.565)$ & $1(0.685)$ \\
Anomalous correlation (inner) & 2 & 3 \\
SigAno & 0.816 & 0.842 \\
Reflections used in refinement & $23764(1661)$ & - \\
Reflections used for $R_{\text {free }}$ & $1264(89)$ & - \\
$R_{\text {work }}$ & $0.150(0.297)$ & - \\
$R_{\text {free }}$ & $0.164(0.319)$ & - \\
CC $C_{\text {work }}$ & 0.952 & - \\
fC $_{\text {free }}$ & 0.948 & - \\
No. of non-hydrogen atoms & 457 & - \\
Macromolecules & 335 & - \\
Solvent & 122 & - \\
Protein residues & 50 &
\end{tabular}


Table 2 (continued)

\begin{tabular}{lll}
\hline & $\begin{array}{l}\text { Cubic insulin } \\
\text { helical }\end{array}$ & $\begin{array}{l}\text { Cubic insulin } \\
\text { MeshAndCollect }\end{array}$ \\
\hline RMS (bonds) & 0.021 & - \\
RMS (angles) & 2.362 & - \\
Ramachandran favored (\%) & 100.00 & - \\
Ramachandran allowed (\%) & 0.00 & - \\
Ramachandran outliers (\%) & 0.00 & - \\
Rotamer outliers (\%) & 0.00 & - \\
Clashscore & 3.90 & - \\
Average $B$ factor & 23.51 & - \\
Macromolecules & 20.76 & - \\
Solvent & 41.56 & - \\
\hline
\end{tabular}

\section{References}

Nanao, M., Basu, S., Zander, U., Giraud, T., Surr, J., Guijarro, M., Lentini, M., Felisaz, F., Sinoir, J., Morawe, C., Vivo, A., Beteva, A., Oscarsson, M., Caserotto, H., Dobias, F., Flot, D., Nurizzo, D., Gigmes, J., Foos, N., Siebrecht, R., Roth, T., Theveneau, P., Svensson, O., Papp, G., Lavault, B., Cipriani, F., Barrett, R., Clavel, C. \& Leonard, G. (2022). J. Synchrotron Rad. 29, 581-590. 


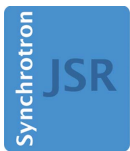

JOURNAL OF SYNCHROTRON RADIATION

ISSN 1600-5775

Received 20 October 202

Accepted 28 January 2022

Edited by Y. Amemiya, University of Tokyo, Japan

Keywords: microcrystallography; macromolecular crystallography; MD3Up high-precision multi-axis diffractometer.

PDB reference: 7qgf
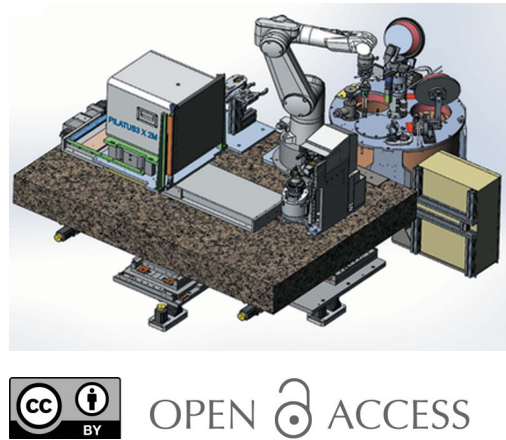

Published under a CC BY 4.0 licence

\section{ID23-2: an automated and high-performance microfocus beamline for macromolecular crystallography at the ESRF}

\author{
Max Nanao, ${ }^{\mathrm{a} *}$ Shibom Basu, ${ }^{\mathrm{b}}$ Ulrich Zander, ${ }^{\mathrm{b}}$ Thierry Giraud, ${ }^{\mathrm{a}}$ John Surr, ${ }^{\mathrm{a}}$ \\ Matias Guijarro, ${ }^{a}$ Mario Lentini, ${ }^{a}$ Franck Felisaz, ${ }^{b}$ Jeremy Sinoir, \\ Christian Morawe, ${ }^{a}$ Amparo Vivo, ${ }^{a}$ Antonia Beteva, ${ }^{a}$ Marcus Oscarsson, ${ }^{a}$ \\ Hugo Caserotto, ${ }^{a}$ Fabien Dobias, ${ }^{a}$ David Flot, ${ }^{a}$ Didier Nurizzo, ${ }^{a}$ Jonathan Gigmes, ${ }^{a}$ \\ Nicolas Foos, ${ }^{\mathrm{a}}$ Ralf Siebrecht, ${ }^{\mathrm{c}}$ Thomas Roth, ${ }^{\mathrm{a}}$ Pascal Theveneau, ${ }^{\mathrm{a}}$ Olof Svensson, ${ }^{\mathrm{a}}$ \\ Gergely Papp, ${ }^{a}$ Bernard Lavault, ${ }^{\mathrm{c}}$ Florent Cipriani, ${ }^{\mathrm{b}}$ Ray Barrett, ${ }^{\mathrm{a}}$ Carole Clavel ${ }^{\mathrm{a}}$ \\ and Gordon Leonard ${ }^{\mathrm{a}}$
}

${ }^{a}$ European Synchrotron Radiation Facility, 71 Avenue des Martyrs, F-38000 Grenoble, France, ${ }^{\mathbf{b} E u r o p e a n}$ Molecular Biology Laboratory, 71 Avenue des Martyrs, 38042 Grenoble, France, and ' ARINAX, 365 Rue de Corporat, 38430 Moirans, France. *Correspondence e-mail: max.nanao@esrf.fr

ID23-2 is a fixed-energy (14.2 keV) microfocus beamline at the European Synchrotron Radiation Facility (ESRF) dedicated to macromolecular crystallography. The optics and sample environment have recently been redesigned and rebuilt to take full advantage of the upgrade of the ESRF to the fourth generation Extremely Brilliant Source (ESRF-EBS). The upgraded beamline now makes use of two sets of compound refractive lenses and multilayer mirrors

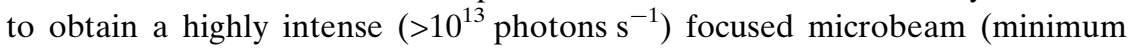
size $1.5 \mu \mathrm{m} \times 3 \mu \mathrm{m}$ full width at half-maximum). The sample environment now includes a FLEX-HCD sample changer/storage system, as well as a state-of-theart MD3Up high-precision multi-axis diffractometer. Automatic data reduction and analysis are also provided for more advanced protocols such as synchrotron serial crystallographic experiments.

\section{Introduction}

Macromolecular microcrystallography is an indispensable tool in modern structural biology. It's ubiquity has made it easy to forget that the ability to analyze very small crystals was not always so simple. Pioneering studies in macromolecular crystallography (MX) using microbeams were performed on microfocus beamlines such as ESRF ID13 (Cusack et al., 1998) which laid the groundwork for many of the techniques and instrumentation currently employed today (Perrakis et al., 1999). At the time, there were no microfocus beamlines dedicated to MX, which was the motivation for the design and construction of the first 'dedicated' macromolecular microcrystallography beamline: ID23-2 (Flot et al., 2010). The design of this beamline emphasized usability and stability in order to make MX microcrystallography accessible to nonexperts in microfocus methods. The efficacy of this type of beamline has been well validated, and the early success of ID23-2 has, in some part, been the motivation for the construction and planning of microfocus beamlines at other synchrotron facilities worldwide (Duran et al., 2013; Evans et al., 2007; Aragão et al., 2018; Gu et al., 2021; Schneider et al., 2021; Yoder et al., 2010; Hirata et al., 2010; Logan et al., 2015).

A small beam with a large flux density enables several types of experiments. The most obvious of these is of course data 
collection from very small crystals. This can be in the form of a single microcrystal mounted in a loop or mesh, data collection from multiple microcrystals in a single loop, or even data collections from multiple crystals in a cell (Axford et al., 2014). Although the ability to use microcrystals offers huge reductions in the resources required to produce larger crystals, the latter case (while exceptional) is illustrative of experiments that are most effectively performed with microbeams. Another example of this type of experiment is the analysis of crystals from native sources, where the amount of protein can be extremely limited - particularly for less abundant proteins (Totir et al., 2012). Microbeams enable a second type of experiment, which is the rastering of the beam through multiple positions in the crystals, with simultaneous data collection. This type of experiment can be invaluable in determining regions of larger crystals with the best properties [for example, highest resolution, best diffraction spot shape, lowest mosaicity or lowest anisotropy (Bowler et al., 2010)], and/or locating a crystal in an optically distorted or opaque drop (for example with crystals grown in lipidic cubic phases).

Small beams also facilitate more advanced data collection strategies in which multiple, usually low-completeness, subdatasets are collected from multiple microcrystals and/or positions on non-microcrystals by rapidly scanning across sample holders and simultaneously collecting data at high frame rates (Liu et al., 2013; Gati et al., 2014; Stellato et al., 2014; Nogly et al., 2015). These so-called 'serial crystallography' experiments can be performed on a wide variety of samples in diverse sample supports and across a wide range of crystal sizes at both cryo and ambient temperatures. They offer a number of potential advantages over traditional 'one crystal, one sample holder' experiments, such as the elimination of cryoprotection, the study of crystals in a more 'native' state, the removal of the requirement to harvest crystals and the possibility to study dynamic processes. Small-beam serial experiments can range from still images collected from individual crystals to hybrid methods in which small oscillation ranges are collected from crystals. In addition, the possibility of stopped-flow serial crystallography in combination with high-speed detectors has already made the study of some biochemical processes possible (Monteiro et al., 2020; Beyerlein et al., 2017; Wang et al., 2014; Schmidt, 2013). Finally, theoretical and experimental work has introduced the exciting possibility that smaller beams could in fact produce less radiation damage to macromolecular crystals because of photoelectron escape (Nave \& Hill, 2005; Cowan \& Nave, 2008; Sanishvili et al., 2011; Dickerson et al., 2020; Storm et al., 2020), particularly at high photon energies. All of these aspects of MX microcrystallography, concomitantly with the design of the ESRF-EBS [Extremely Brilliant Source (Raimondi, 2016)] with its dramatic improvement in brilliance, were the motivations for upgrading the ID23-2 beamline.

\section{Optical layout of ID23-2}

The goals of the optical upgrade of ID23-2 were to provide a smaller beam size in addition to the proven $\sim 6 \mu \mathrm{m} \times 4 \mu \mathrm{m}$
$[\mathrm{H} \times \mathrm{V}$, full width at half-maximum (FWHM)] beam size with roughly the same flux. X-rays are produced by a single $1.6 \mathrm{~m}$ long $20.2 \mathrm{~mm}$-period undulator with a minimum gap of $11 \mathrm{~mm}$. The ID23-2 insertion device is located on the upstream segment of a canted straight section [the downstream segment contains the insertion device for beamline ID23-1 (Nurizzo et al., 2006)]. The beam proceeds through the front-end into the optical hutch, where the beam tails are reduced with a set of high-power primary slits $28.2 \mathrm{~m}$ from the source (Fig. 1). The high-power primary slits are a pair of liquid-cooled copper blocks with a $7 \mathrm{~mm} \times 3 \mathrm{~mm}(\mathrm{H} \times \mathrm{V})$ hole bored through the block. These blocks are mounted on horizontal and vertical translation tables (Flot et al., 2010). A liquid-nitrogen-cooled $\mathrm{Si}(111)$ monochromator selects a fixed energy of $14.2 \mathrm{keV}$ $30 \mathrm{~m}$ from the source for ID23-2 and also deflects the beam laterally, away from the ID23-1 beam originating from the downstream cant, leaving ample room between the two beamlines for downstream optics and sample environments. The monochromator design remained unchanged compared with the original installation (Flot et al., 2010), with the exception of the introduction of a linear incremental encoder on the Bragg rotation of the monochromator and a fully vacuum-compatible UHV microjack for monochromator Bragg angle fine adjustment.

Vertical and horizontal focusing are decoupled, and are achieved by two transfocators containing 1D beryllium compound refractive lens (CRL) sets (for vertical focus) and two sets of elliptically figured multilayer mirrors (for horizontal focus). Each of these four elements can be translated in and out of the beam depending on the desired beam sizes. The general strategy is to use lenses from the first transfocator in combination with the first mirror to produce the largest beam, and lenses from the second transfocator together with a second mirror for the smallest beam. However, higher aspect ratio beam profiles can be obtained by mixing and matching, and, indeed, using lenses from both transfocators.

\section{Vertical focusing}

After lateral deflection by the monochromator, the beam passes through a set of JJ X-Ray ib-c30-hv slits (https:// www.jjxray.dk/) (31.55 $\mathrm{m}$ from the source), and into the first transfocator (32 $\mathrm{m}$ from the source). The transfocator assembly is mounted on a Q-sys (http://www.q-sys.eu/) fouraxis positioning table and can be controlled via pseudo motors in BLISS (BeamLine Instrument Support Software), a Pythonbased open-source ESRF software suite for high-level experimental control (Guijarro et al., 2018). The transfocator is a standard ESRF design with nine pneumatically actuated axes (Fig. 2).

Pinholes of $2 \mathrm{~mm}$ diameter are mounted in the first and last positions to facilitate alignment. Different combinations of lenses were mounted in stacks on each pneumatic axis, corresponding to the analytical calculations (Table 1). Additionally, two larger radius lenses were included in each transfocator to permit fine tuning of the focal distance. After the first transfocator, the beam reaches a second set of slits 
$39 \mathrm{~m}$ from the source. At $40 \mathrm{~m}$, the beam reaches the second transfocator. This is identical to the first, with the exception of the lens configuration (Table 1). Because lens stacks are pneumatically actuated, the vertical beam sizes at the sample position can be rapidly $(<1 \mathrm{~s})$ changed by a simple pulldown menu. The user simply selects the desired vertical beam size, and an internal lookup table contains the corresponding set of lens stacks to insert into the beam. Sizes from the minimum $(2.9 \mu \mathrm{m}$ FWHM) to $40 \mu \mathrm{m}$ are available without realignment of the beam position. In order to determine the beam size, a $100 \mu \mathrm{m}$ boron microfilament with a $5 \mu \mathrm{m}$ tungsten core (Goodfellow, Lille, France) was mounted on the diffractometer and rastered vertically and horizontally through the beam. X-ray intensity was recorded downstream of the wire on a PIN diode (PIN-10DPI, OSI Optoelectronics, Hawthorn, USA). The resulting beam profile obtained after differentiation of the S-shaped raw intensity curve is shown in Figs. $3(b)$ and $3(d)$.

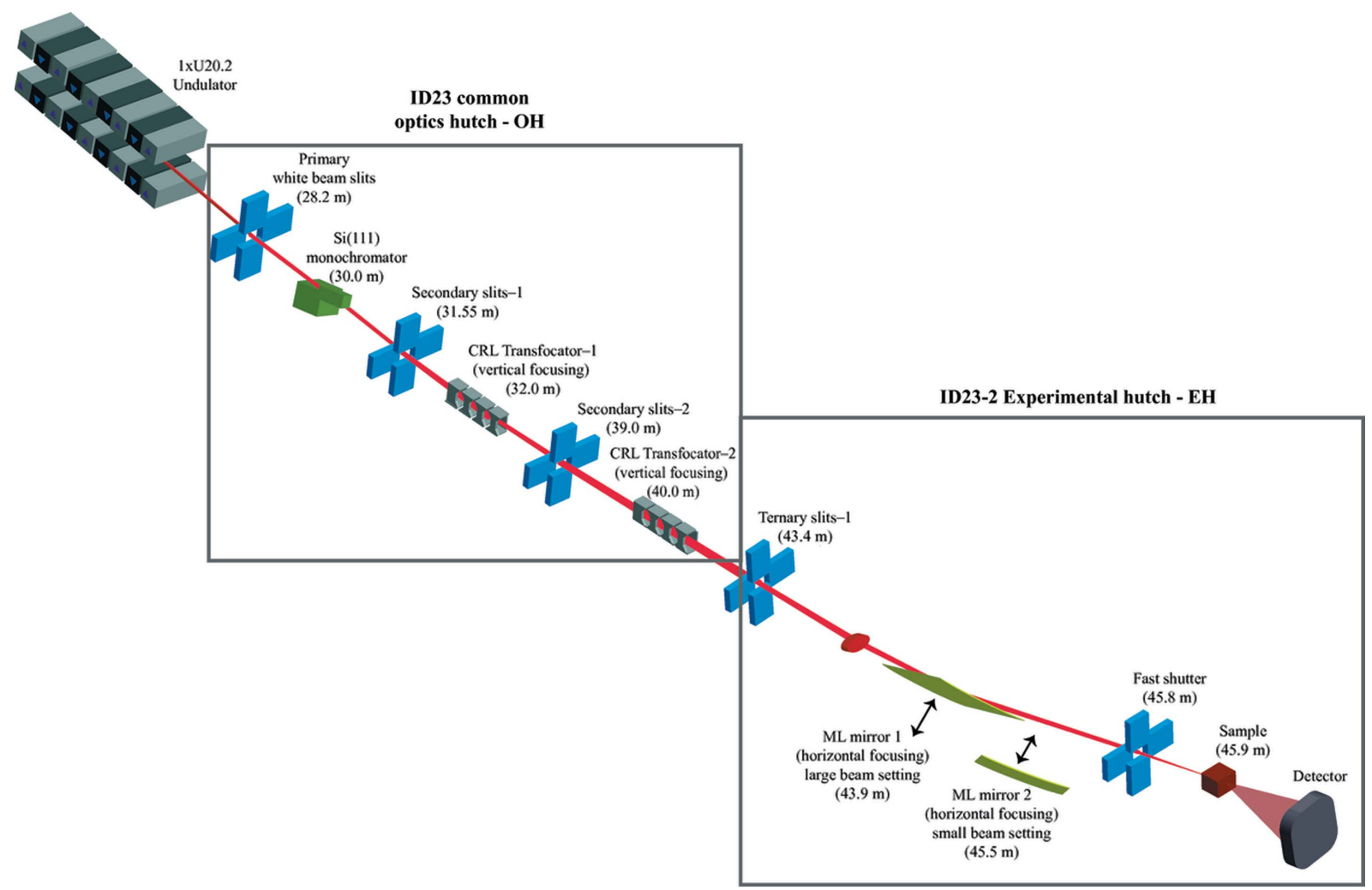

Figure 1

Optical layout of ID23-2. Distances from the source are shown in parentheses. ID23-2 shares a common optical hutch with ID23-1. In the optics hutch (rectangle on the left), energy selection and beam deflection are achieved by the monochromator (green) and vertical focusing is performed by sets of CRLs in transfocators. In the experimental hutch (shown in the rectangle on the right), the beam is then horizontally focused by one of the two multilayer mirrors.

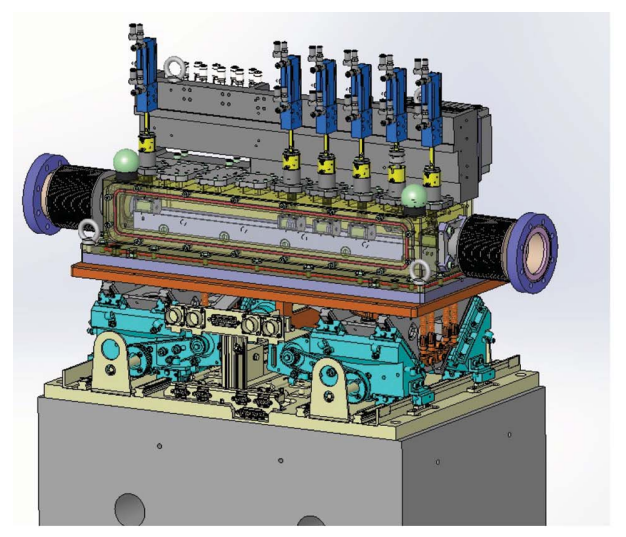

Figure 2

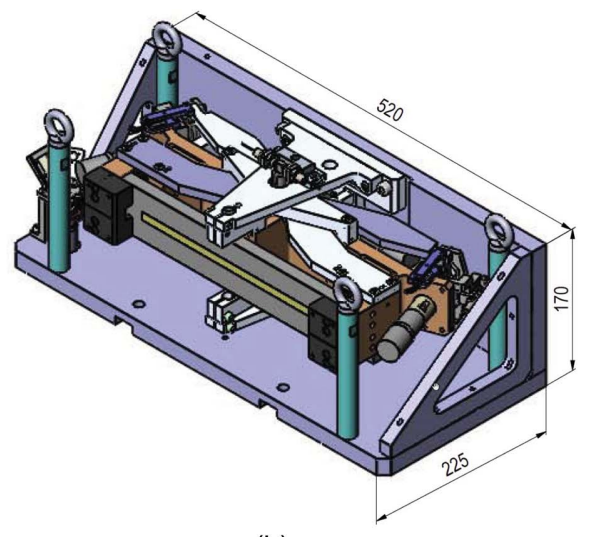

(b)

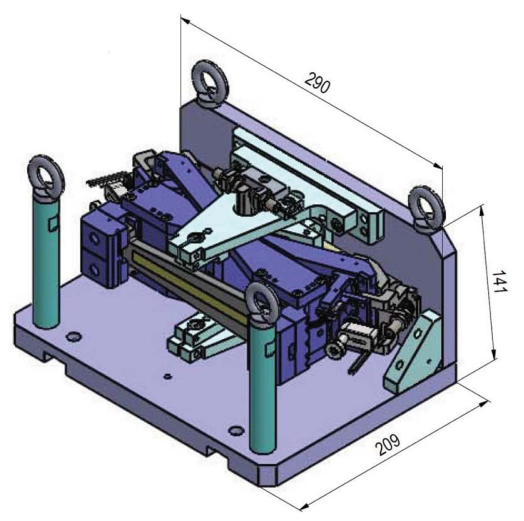

(c)

(a) Transfocator CAD-drawing. Pneumatic axes (blue) actuate the insertion of lens pack holders into the beam path and onto a high-precision V-rail for mutual lens pack alignment. Alignment (rotation and translation) of the transfocator is achieved through a Q-Sys motion platform (cyan). (b) Largebeam and $(c)$ small-beam HFM assembly. The mirrors are shown in gray, with the illuminated region in yellow. Dimensions are given in millimetres. 
Table 1

Summary of the beamline parameters, including source, optical configuration, X-ray beam characteristics and the experimental setup for ID23-2 at the ESRF.

\begin{tabular}{|c|c|c|}
\hline Beamline name & \multicolumn{2}{|l|}{ ID23-2 } \\
\hline Source type & \multicolumn{2}{|c|}{$1 \times 1.6 \mathrm{~m} 20.2 \mathrm{~mm}$-period undulator } \\
\hline Horizontal emittance (pm rad) & \multicolumn{2}{|l|}{132} \\
\hline Vertical emittance (pm rad) & \multicolumn{2}{|l|}{5} \\
\hline Monochromator & \multicolumn{2}{|l|}{$\operatorname{Si}(111)$} \\
\hline Energy (keV) & \multicolumn{2}{|l|}{14.2} \\
\hline Horizontal photon source size ( $\mu \mathrm{m}$ RMS) & \multicolumn{2}{|l|}{30.3} \\
\hline Vertical photon source size ( $\mu \mathrm{m} \mathrm{RMS})$ & \multicolumn{2}{|l|}{4.5} \\
\hline Horizontal photon divergence ( $\mu$ rad RMS) & \multicolumn{2}{|l|}{6.9} \\
\hline Vertical photon divergence ( $\mu$ rad RMS) & \multicolumn{2}{|l|}{5.6} \\
\hline \multicolumn{3}{|l|}{ Vertical focusing } \\
\hline Focusing elements & \multicolumn{2}{|l|}{ 1D CRLs in two transfocators } \\
\hline Lens material & \multicolumn{2}{|l|}{$\mathrm{Be}$} \\
\hline Transfocator & Large beam & Small beam \\
\hline Axis $1(\mathrm{~mm})$ & $2 \mathrm{~mm}$ alignment pinhole & $2 \mathrm{~mm}$ alignment pinhole \\
\hline Axis $2[$ No. of lenses $\times$ radius $(\mu \mathrm{m})]$ & $1 \times 200$ & $1 \times 200$ \\
\hline Axis $3(\mu \mathrm{m})$ & $5 \times 200$ & $12 \times 200$ \\
\hline Axis $4(\mu \mathrm{m})$ & $1 \times 500$ & $1 \times 500$ \\
\hline Axis $5(\mu \mathrm{m})$ & $1 \times 300$ & $1 \times 300$ \\
\hline Axes 6-7 $(\mu \mathrm{m})$ & Unused & Unused \\
\hline Axis $8(\mu \mathrm{m})$ & $2 \mathrm{~mm}$ alignment pinhole & $2 \mathrm{~mm}$ alignment pinhole \\
\hline Transfocator efficiency (\%) & 93 & 88 \\
\hline Vertical demagnification ratio & $2.4 \times$ & $8 \times$ \\
\hline \multicolumn{3}{|l|}{ Horizontal focusing } \\
\hline Mirror assembly & Large beam & Small beam \\
\hline Horizontal focusing mirror (HFM) & Bendable tangential mirror & Bendable tangential mirror \\
\hline Incident angle on HFM (mrad) & 18 & 18 \\
\hline Slope error of HFM ( $\mu$ rad RMS) & 0.50 & 0.57 \\
\hline Horizontal demagnification ratio & $21 \times$ & $91 \times$ \\
\hline \multicolumn{3}{|l|}{ Sample position } \\
\hline Beam size $(H \times V, F W H M)(\mu \mathrm{m})$ & $4.7 \times 6.0$ & $1.5 \times 3.0$ \\
\hline Flux (photons s ${ }^{-1}$ ) & $1.8 \times 10^{13}$ & $1.5 \times 10^{13}$ \\
\hline Diffractometer & \\
\hline Sample mounting & & \\
\hline Detector type & \multicolumn{2}{|l|}{ CMOS Hybrid Pixel-Array } \\
\hline Detector model & \multicolumn{2}{|c|}{ Dectris PILATUS3 X 2M (450 $\mu \mathrm{m}$ Si sensor $)$} \\
\hline
\end{tabular}

The small-beam HFM is a $140 \mathrm{~mm}$ long bendable $\left[\mathrm{W} / \mathrm{B}_{4} \mathrm{C}\right]_{100}$ laterally graded multilayer mirror with $2.5 \mathrm{~nm}$ layer spacing (at the center) and provides a $91 \times$ demagnification ratio. Coating and metrology of the mirror were performed at the ESRF. The center of this mirror is $500 \mathrm{~mm}$ upstream of the sample position, and $45.5 \mathrm{~m}$ from the source, also working at an $18 \mathrm{mrad}$ incidence angle. The mirror mechanics are bent with two vacuum New Focus picomotors. Encoding is facilitated by optical encoders (MicroE Mercury series) [Fig. 2(c)]. The RMS slope error was measured (by optical metrology) to be $0.57 \mu \mathrm{rad}$ over the central $130 \mathrm{~mm}$ (and $0.37 \mu \mathrm{rad}$ for the central $120 \mathrm{~mm}$ ) in the bender system. The minimum beam size was measured to be $1.5 \mu \mathrm{m}$ FWHM [Fig. 3(c)]. Photon flux in the small- and large-beam settings was calculated as per Owen $e t$ al. (2009) from diode readings to be $1.5 \times 10^{13}$ and $1.8 \times 10^{13}$ photons s $^{-1}$, respectively, and are unaffected by the vertical beam size.

The same large stroke translation as the larger beam mirror is employed to translate the mirror in and out of the beam. The design of independent vertical and horizontal focusing enables fast switching between largeand small-beam settings by moving

\section{Horizontal focusing}

The large-beam horizontally focusing mirror (HFM) is a $240 \mathrm{~mm}$-long bendable $\left[\mathrm{W} / \mathrm{B}_{4} \mathrm{C}\right]_{100}$ coated multilayer graded mirror with $2.5 \mathrm{~nm} d$-spacing, $2.1 \mathrm{~m}$ from the sample position and $43.9 \mathrm{~m}$ from the source, and provides a $21 \times$ demagnification ratio. This mirror works at an $18 \mathrm{mrad}$ incidence angle. Coating and metrology of the mirror were performed at the ESRF. The initially flat mirror is elliptically figured using a dual actuator bender giving a root-mean-square (RMS) slope error (measured by optical metrology) of $0.50 \mu \mathrm{rad}$ after mounting in the bender. The mirror is mounted in the same mechanical support as previously described (Flot et al., 2010) and shown in Fig. $2(b)$. The bending moments are applied to the mirror via the mechanical support using two stepper motor actuated jacks, and the position is read by two optical encoders (MicroE Mercury series https://www.celeramotion.com/). A large-stroke $(35 \mathrm{~cm})$ translation allows the entire mirror in its bender to be translated into and out of the beam ( $y$ direction). The optimized beam size was measured to be $4.7 \mu \mathrm{m}$ FWHM as shown in Fig. 3(a), which is the normal operating setting, but unfocused horizontal beam sizes up to $18 \mu \mathrm{m}$ FWHM are also possible. the HFMs in/out of the beam path (shown in Fig. 1). However, in practice, once the $y$ position is optimized relative to the incoming beam, the small-beam HFM no longer needs to be moved. Once the first HFM is moved into the beam, the table is translated $54 \mathrm{~cm}$ in the $y$ direction. This motion is highly repeatable, with the beam position within $\pm 1 \mu \mathrm{m}$ of the initial position, after the full $54 \mathrm{~cm}$ movement, and takes $3 \mathrm{~min}$. The incidence angles of the two mirror systems were deliberately chosen to be the same (18 mrad) so that only a translation of the downstream experimental table between the reflected beams is required, without rotation.

Several devices have been installed for beam alignment and diagnostics. Three sets of motorized translations, containing YAG, diamond or carbon foils, can be inserted into the beam path via BLISS. Permanently installed BASLER cameras with visible-light optics can be used to visualize the beam image on fluorescent screens via LIMA (Petitdemange et al., 2014). Diodes, connected to Keithley (Tektronix, Beaverton, OR/ USA) pico-ammeters, allow for the alignment of upstream optical elements when the beam viewer axis is moved to the foil-containing position. These beam viewers/diodes are installed in the white beam after the primary slits, immediately 
Large-beam setting

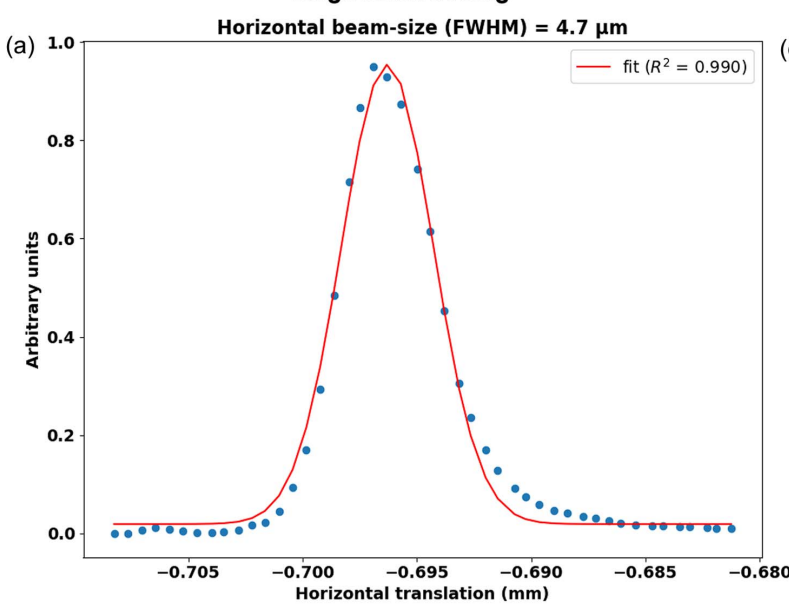

(a)

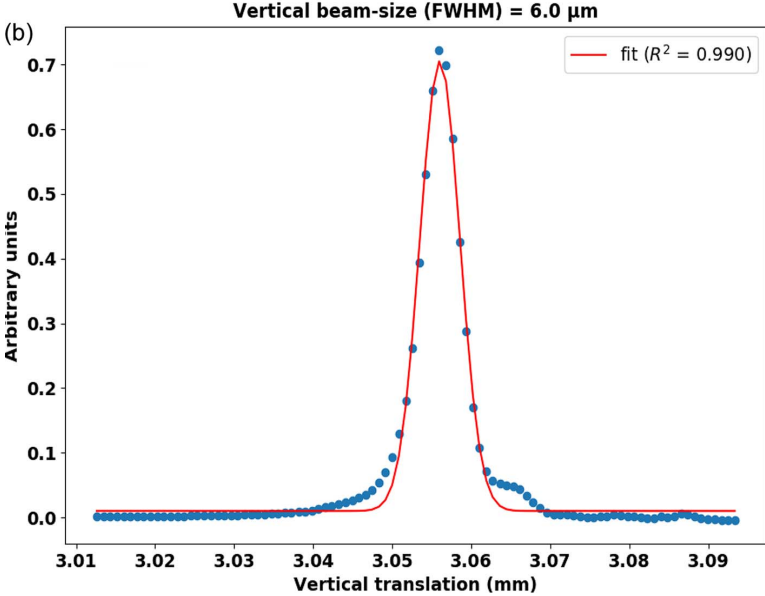

Small-beam setting
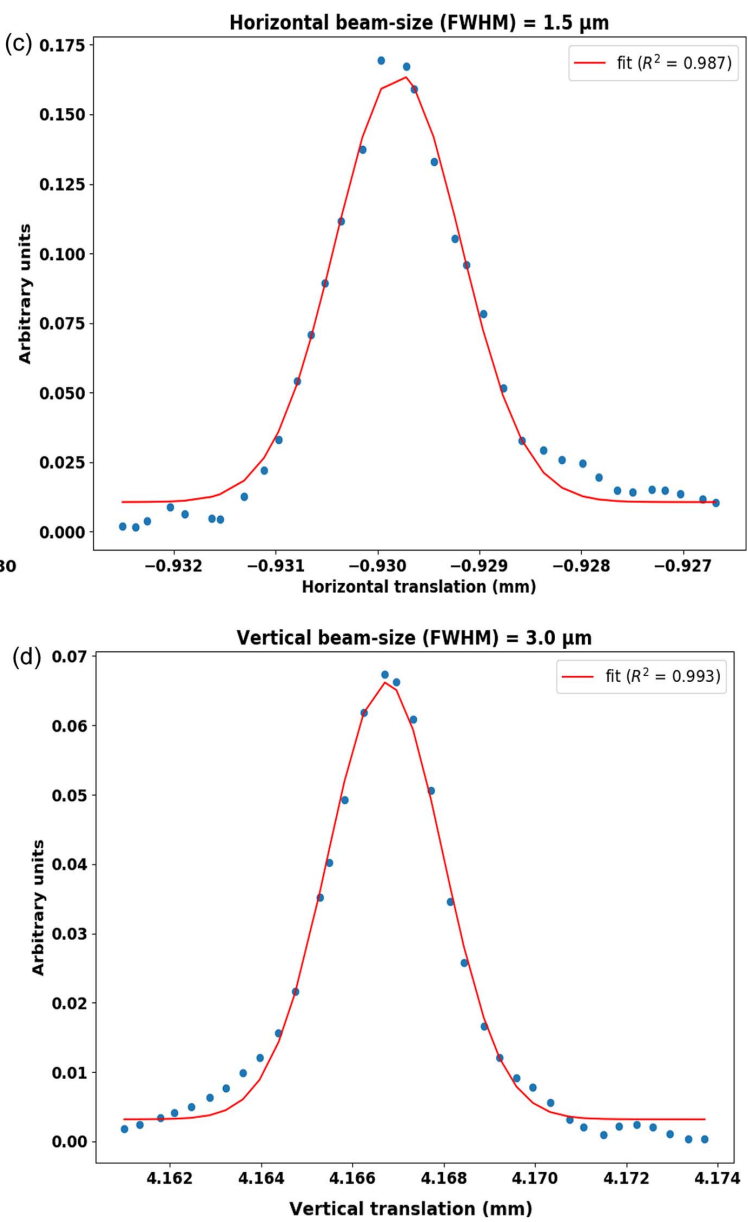

Figure 3

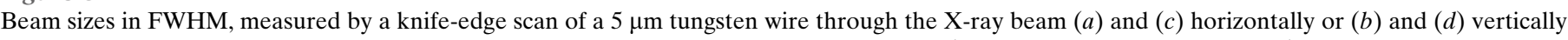
with readout from a downstream calibrated PIN diode. Fitting was performed in $P y M C A$ (https:/github.com/vasole/pymca).

after the monochromator, immediately after the first transfocator, and after the second transfocator at 28.80, 31.00, 33.00 and $40.95 \mathrm{~m}$ from the source, respectively.

\section{Sample environment}

Changes in temperature can cause the beam and sample to drift in position. In order to improve the thermal stability of the experimental hutch, an ante room was installed to buffer the temperature changes caused by entering the experimental hutch. Additionally, a new, higher capacity air-conditioning unit was installed, with exit grates replaced by fabric ducting, to better distribute the air flow within the hutch, and to reduce air turbulence. Together, these changes improve the thermal stability to $\pm 0.5^{\circ} \mathrm{C}$.

In addition to the selected primary focusing elements, the beam passes through an attenuator block of the same design as on ID30B (McCarthy et al., 2018), with the same configuration of carbon and aluminium filters (1 and $2 \mathrm{~mm}$ carbon; $0.20,0.35,0.50,1.00$ and $1.50 \mathrm{~mm}$ aluminium) before the first mirror. These attenuators are on a series of pneumatic supports, and are controlled via BLISS. In addition, slits have been installed upstream of both mirror systems in order to control the divergence of the reflected beam, and also to optimize mirror bending by rastering a pencil beam across the mirror surface. JJ X-ray slits are installed upstream of the small-beam mirror vessel and a rotary fast shutter (von Stetten et al., 2020) is attached to the MD3 diffractometer and controlled by the MD3 PMAC controller via an ICEPAP motor controller (Janvier et al., 2013). Sample storage and changing are handled by a FLEX-HCD dewar and sample changer system (Fig. 4) (McCarthy et al., 2018). In contrast to other ESRF MX beamlines, with the exception of MASSIF-1, all 23 sample cells are configured to hold Universal Pucks (Uni-Pucks). This allows for up to 368 sample holders to be evaluated before the user or beamline staff need to enter the hutch to reload the HCD. Robust error handling has been designed into both hardware and software, with optical checks for sample presence and alignment on the FLEX-HCD and inductively on the MD3 goniometer head. Dedicated control software and GUI based on JLib java toolbox (EMBLEM Technology Transfer GmbH, Heidelberg, Germany; http:// software.embl-em.de) manage all FLEX-HCD operations, including sample loading, dewar refilling, puck detection and synchronization between the diffractometer, FLEX robotic arm and the HCD dewar. 


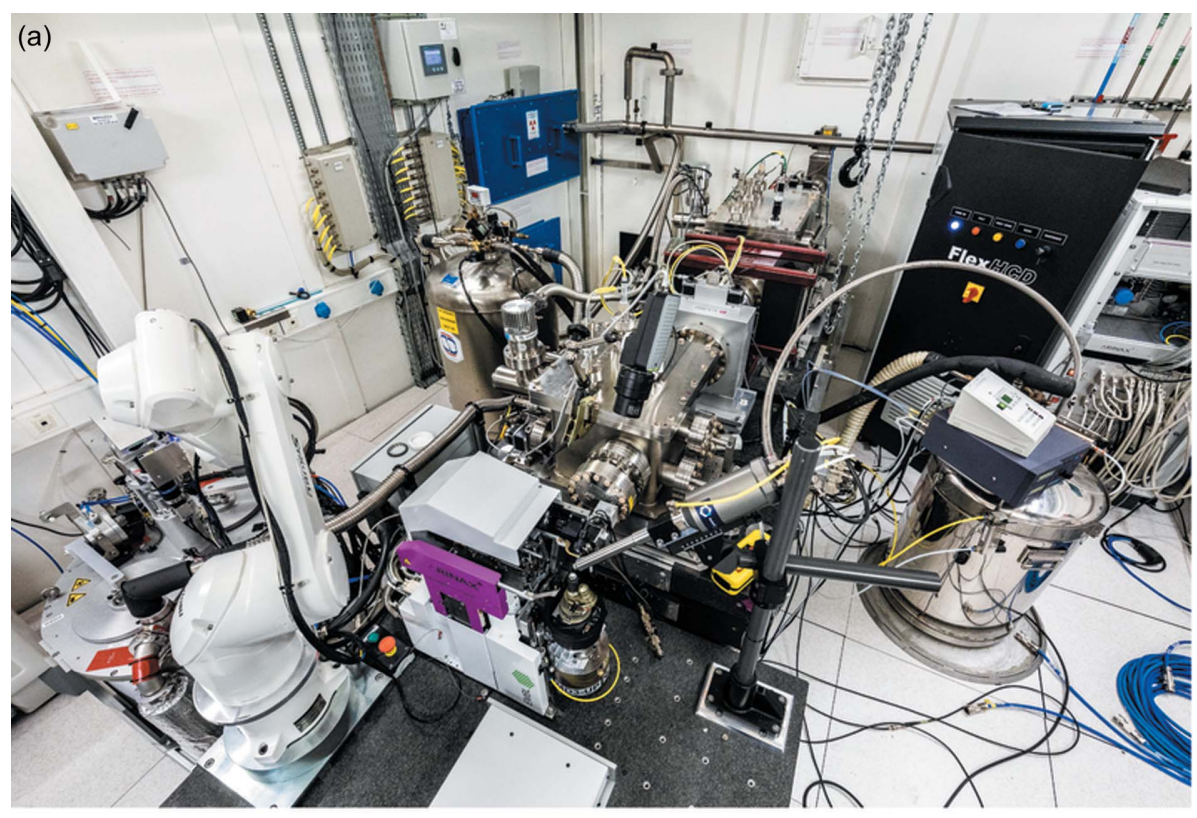

(b)

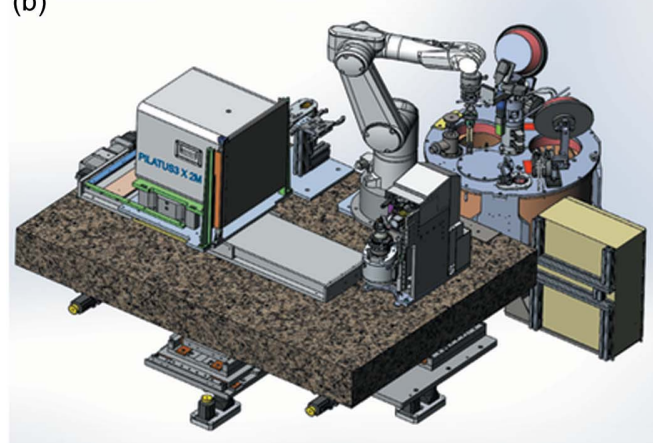

Figure 4

ID23-2 sample environment. (a) Photograph of the sample environment (Stef Cande, ESRF), (b) MD3Up, detector and FLEX-HCD, (c) close-up of MD3Up.

An MD3Up diffractometer (ARINAX, Moirans, France; see Fig. 4) has been installed on the experimental table. This state-of-the-art device offers better than a $200 \mathrm{~nm}$ sphere of confusion in diameter, measured optically. MD3Up offers rapid $\left(<1 \mu \mathrm{m}\right.$ following error at $\left.15 \mathrm{~mm} \mathrm{~s}^{-1}\right)$ vertical and horizontal movements with the sample alignment motors, critical for rapid rastering through samples. An MK3 minikappa device (Cipriani et al., 2007) is also installed, which allows for re-alignment of the crystal - for example to align a long unit cell with the goniometer rotation axis. Because horizontally mounted MK3 devices have a relatively large sphere of confusion, mini-kappa usage was only possible in limited situations with the previous MD2M (horizontal omega axis) diffractometer. Measurement of the sphere of confusion at the sample position with the kappa device in this vertical orientation confirmed no detectable degradation in the sphere of confusion with the kappa unit closed, and only minor degradations at 'open' kappa angles [80 nm at $k=0^{\circ}$ (closed), $110 \mathrm{~nm}$ at $k=120^{\circ}$ and $130 \mathrm{~nm}$ at $\left.k=180^{\circ}\right]$ and as a result is permanently mounted. Additionally, a crystallization plate gripper is now available on the beamline, compatible with some SBS-formatted crystallization plates. Finally, a
DECTRIS Pilatus3 2M with a $450 \mu \mathrm{m}$ silicon sensor (Dectris AG, BadenDaettwil, Switzerland) is installed on a motorized translation table, which is driven by an ICEPAP motor controller and is available in the BLISS environment (Guijarro et al., 2018). Detector triggering is controlled by the MD3Up PMAC controller. Detector parameters and image writing are mediated by the LIMA software (https:/lima1. readthedocs.io).

\section{Software}

The $M X C U B E 3$ beamline control program (Oskarsson et al., 2018; Oscarsson et al., 2019) provides a powerful and intuitive interface for both routine data collections as well as more sophisticated semi and fully automated workflows (Brockhauser et al., 2012; Zander et al., 2015). Once collected, data are automatically processed using XDSAPP, GRENADES, xia2 and autoproc (Vonrhein et al., 2011; Krug et al., 2012; Monaco et al., 2013; Winter et al., 2018). Furthermore, input files are automatically generated for $X D S$ (Kabsch, 2010). Data collection parameters and processed data are made available with a web interface using the $I S P y B$ database (Delagenière et al., 2011) and EXI front-end (http://exi.esrf. $\mathrm{fr} /$ ). Data collected with the mesh and collect serial crystallography workflow (Zander et al., 2015) are automatically processed as follows: individual sub-datasets are integrated with $X D S$. Once an initial pass has been completed, the dataset with the highest overall $\langle I / \sigma(I)\rangle$ is used as the reference dataset, and the XDS CORRECT step is re-run for all other datasets using this dataset as the REFERENCE_DATA_SET. The resulting consistently indexed set of partial datasets is then submitted for grouping with $c c$ Cluster and CODGAS (Zander et al., 2016; Santoni et al., 2017; Foos et al., 2019).

Once the data have been integrated, several downstream structure solution pipelines are available. Several sources for molecular replacement search models are used, in two categories. In the first mode, the unit-cell parameters are compared with existing entries in the Protein Data Bank [PDB (Berman et al., 2000)] using the program SAUC (McGill et al., 2014). Positive matches are downloaded from the PDB. The second category provides significantly more flexibility to the user, and allows the user to define multiple components in the crystal, and/or alternative search models via EXI. The models can either be directly uploaded, or a UniProt ID can be provided. In the latter case, the UniProt ID is mapped to 
existing entries in the PDB and also the EBI Alphafold (Jumper et al., 2021) database (https://alphafold.ebi.ac.uk/). Molecular replacement is performed in PHASER (McCoy et $a l ., 2007)$, and the results are uploaded to $I S P y B .2 F_{\mathrm{o}}-F_{\mathrm{c}}$ and $F_{\mathrm{o}}-F_{\mathrm{c}}$ electron density maps are viewable within $E X I$ via UGLYmol (Wojdyr, 2017) in a web browser, and all log files can be directly downloaded. Similarly, either individual ligands or collections of ligands can be uploaded to $I S P y B$ in SMILES, MOL2 or SDF format, and ligand fitting is performed using Coot 'find ligand' (Emsley et al., 2010). If an anomalous signal is detected, the data are submitted to SHELXC/D/E (Sheldrick, 2010; Monaco et al., 2013) for automatic phasing with experimental electron density maps and partial models available for display and download as above.

\section{Pre- and post-EBS data statistics}

The diversity of projects and user workflows make any rigorous statistical comparisons of merging statistics difficult. Nevertheless, the large number of datasets that are auto-
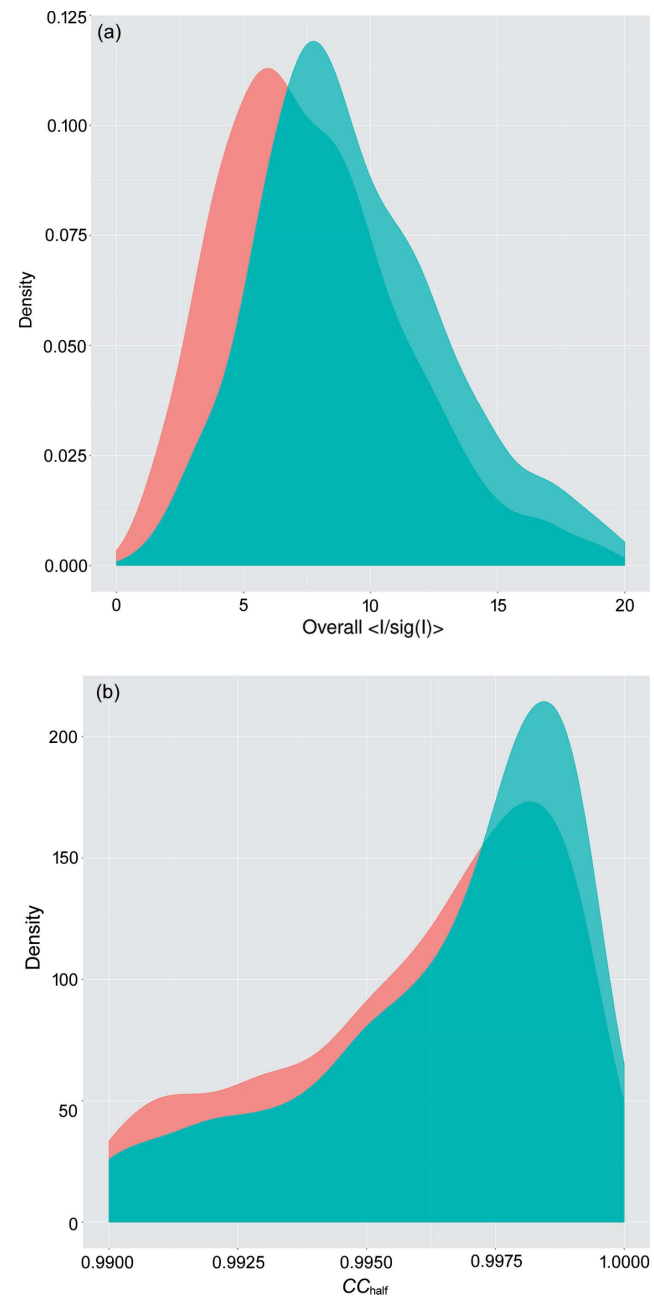

Figure 5

(a) Kernel densities of overall $\langle I / \sigma(I)\rangle$ for the six months of operation preceding the EBS upgrade (red) and six months of operation post-EBS upgrade (green). (b) Overall $C C^{1 / 2}$ values. matically processed allows for some comparisons of datasets pre- and post-EBS, provided that caution is used in their (over)interpretation. All beamline upgrades were completed in the middle of 2017, 1.5 years before the EBS upgrade. The six-month periods leading up to the shutdown in 2018, and the first six months of operation in 2021 were chosen as the analysis period. Datasets from ID23-2 were gathered from EXI/ISPyB and filtered to remove screening and poorly indexed/integrated datasets by selecting those with overall completeness $>90 \%$, overall $C C^{1 / 2}>0.4$ and overall $R_{\text {merge }}$ $<0.4$. Plots of smoothed kernel density estimates were calculated using the geom_density function of ggplot2 (https:// ggplot2.tidyverse.org/) within $R$ (https://www.R-project.org/). This function uses the $R$ density (https://www.rdocumentation. org/packages/stats/versions/3.6.2/topics/density) function to produce the kernel density, using a Gaussian kernel and produces curves of frequencies that are less sensitive to histogram bin widths than simple histograms. A significant improvement to the overall $\langle I / \sigma(I)\rangle$ can be observed after the EBS [Fig. 5(a)]. The mean overall $\langle I / \sigma(I)\rangle$ values pre- $(n=$ $900)$ and post- $(n=924)$ EBS were 7.75 and 9.78 , respectively. A Welch two-sample $t$-test (Welch, 1947) was performed in $R$ (https://www.R-project.org/). This modification of the standard $t$-test does not assume equal variances or sizes between the two populations and yielded a $p$-value of $2.2 \times 10^{-16}$, indicating that the populations are different. While not as dramatic as for $\langle I / \sigma(I)\rangle$, the $R_{\text {merge }}$ values also improved significantly ( $p$-value of $1.45 \times 10^{-6}$ ) from pre- to post-EBS with mean values of 22.5 and $19.2 \%$, respectively. Interestingly, the overall $C C^{1 / 2}$ (Karplus \& Diederichs, 2012) values were not significantly different between the two populations ( $p$-value of 0.928$)$, although there was a very modest shift in the distribution of $C C^{1 / 2}$ values [Fig. 5(b)]

\section{Example data collections}

The high flux density of ID23-2 makes analysis of microcrystals the most common use for the beamline. However, the microbeam is also routinely used to attain higher multiplicity datasets from larger single crystals. This is typically achieved by collecting datasets from multiple positions on a crystal, or by using helical data collections (Flot et al., 2010). One example of the latter can be seen in Table 2, taken with the small-beam setting $(1.5 \mu \mathrm{m} \times 3 \mu \mathrm{m}$ FWHM $)$. In this example, a large $(300 \mu \mathrm{m} \times 50 \mu \mathrm{m} \times 50 \mu \mathrm{m})$ cubic insulin crystal was used to collect 3600 frames helically with heavy attenuation, yielding a flux of $1 \times 10^{11}$ photons s $^{-1}$ at an oscillation step of $0.1^{\circ}$ with $30 \mathrm{~ms}$ exposures, in $7 / 8$ multibunch mode with $200 \mathrm{~mA}$ ring current. Despite the extremely non-optimal energy, these data were of sufficient quality that experimental phases could be determined from the very weak sulfur anomalous signal $\left[f^{\prime \prime}\right.$ at $14.2 \mathrm{keV}=0.2 \mathrm{e}^{-}$, estimated anomalous signal of $0.4 \%$ (http://bmsc.washington.edu/scatter)]. SHELXC/D/E (Sheldrick, 2010) and CRANK2 (Pannu et al., 2011) were used for phasing and density improvement, followed by cycles of manual building in Coot (Emsley et al., 2010) and refinement in REFMAC5 (Murshudov et al., 2011). 
Table 2

Data collection and refinement statistics.

Statistics for the highest-resolution shell are shown in parentheses. For the mesh and collect data, the average cell edge and range are provided. A refinement was not performed for these data.

\begin{tabular}{|c|c|c|}
\hline & $\begin{array}{l}\text { Cubic insulin } \\
\text { helical }\end{array}$ & $\begin{array}{l}\text { Cubic insulin } \\
\text { mesh and collect }\end{array}$ \\
\hline Wavelength $(\AA)$ & 0.873 & 0.873 \\
\hline No. of crystals & 1 & 142 \\
\hline Resolution range $(\AA)$ & $\begin{array}{l}39.28-1.203 \\
\quad(1.246-1.203)\end{array}$ & $\begin{array}{l}32.07-1.750 \\
(1.80-1.75)\end{array}$ \\
\hline Space group & $I 2{ }_{1} 3$ & $I 2{ }_{1} 3$ \\
\hline \multirow[t]{2}{*}{ Unit cell } & $a=b=c=78.50$ & $\begin{array}{c}a=b=c=78.47 \\
(78.27-78.73)\end{array}$ \\
\hline & $\alpha=\beta=\gamma=90$ & $\alpha=\beta=\gamma=90$ \\
\hline Total reflections & $2269388(146102)$ & $1257717(95649)$ \\
\hline Unique reflections & $25126(2395)$ & $15814(1184)$ \\
\hline Multiplicity & $90.3(58.7)$ & $79.53(80.78)$ \\
\hline Completeness (\%) & $99.45(95.30)$ & $100(99.7)$ \\
\hline$\langle I / \sigma(I)\rangle$ & $30.66(1.26)$ & $25.48(1.36)$ \\
\hline Wilson $B$-factor & 17.03 & 13.18 \\
\hline$R_{\text {meas }}$ & $0.106(2.697)$ & $0.155(4.143)$ \\
\hline$C C_{1 / 2}$ & $1(0.565)$ & $1(0.685)$ \\
\hline Anomalous correlation (inner) & 2 & 3 \\
\hline SigAno & 0.816 & 0.842 \\
\hline Reflections used in refinement & $25010(2395)$ & - \\
\hline Reflections used for $R_{\text {free }}$ & $1264(129)$ & - \\
\hline$R_{\text {work }}$ & $0.0468(0.0768)$ & - \\
\hline$R_{\text {free }}$ & $0.0442(0.0755)$ & - \\
\hline$C C_{\text {work }}$ & $0.951(0.736)$ & - \\
\hline$C C_{\text {free }}$ & $0.959(0.706)$ & - \\
\hline No. of non-hydrogen atoms & 459 & - \\
\hline Macromolecules & 396 & - \\
\hline Solvent & 63 & - \\
\hline Protein residues & 50 & - \\
\hline RMS (bonds) & 0.016 & - \\
\hline RMS (angles) & 1.66 & - \\
\hline Ramachandran favored (\%) & 100.00 & - \\
\hline Ramachandran allowed (\%) & 0.00 & - \\
\hline Ramachandran outliers (\%) & 0.00 & - \\
\hline Rotamer outliers (\%) & 0.00 & - \\
\hline Clashscore & 3.90 & - \\
\hline Average $B$-factor & 22.63 & _- \\
\hline Macromolecules & 19.55 & - \\
\hline Solvent & 42.04 & - \\
\hline
\end{tabular}

Substructure search was performed in SHELXD with the DSUL 3 keyword specified, using data to $2.5 \AA$ resolution and yielded a substructure solution with a $\mathrm{CFOM}$ of $42.2, C C_{\text {all }}$ of 24.75 and $C C_{\text {weak }}$ of 17.5 after 4000 cycles. Strong contrast was observed between the two hands in SHELXE, with a final CC of the partial model of $41.5 \%$ after two automatic building cycles. Calculation of a model phased anomalous difference map in ANODE (Thorn \& Sheldrick, 2011) revealed peak heights of $S$ positions of 14.9, 14.9, 12.9, 12.9, 12.7 and 12.6 for CYS 19B, CYS 20A, CYS 7A, CYS11A, CYS 7B and CYS 6A, respectively. Experimental electron density is shown in Fig. 6. The refined structure has been deposited in the PDB with the accession code 7qgf, and the raw images have been made available on Zenodo (https://zenodo.org/record/5761266).

A second example of achieving higher multiplicity and signal-to-noise compared with what is possible from a single crystal is the use of the mesh and collect SSX approach (Zander et al., 2016). The crystallization of insulin microcrystals was set up using a 24-well sitting drop plate. A volume

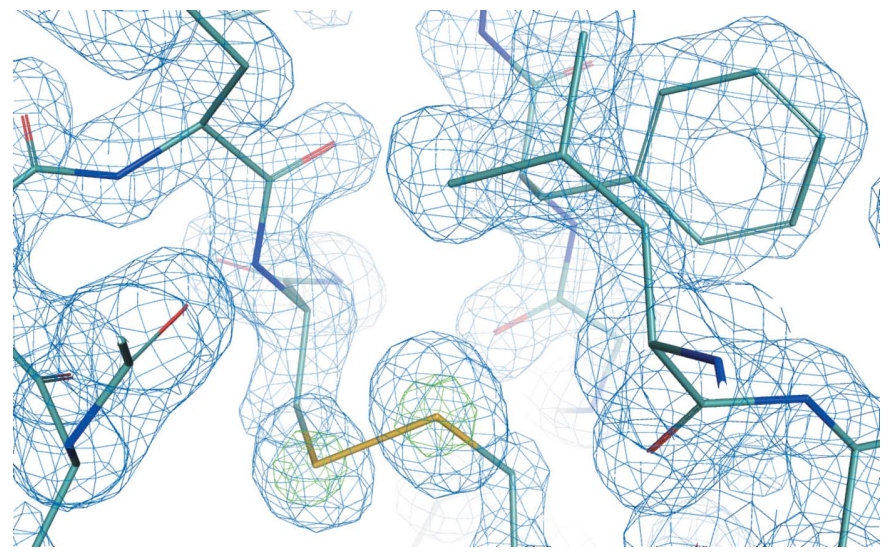

Figure 6

Experimental electron density (blue) from native sulfur anomalous phasing of cubic insulin on data collected at $E=14.2 \mathrm{keV} / 0.873 \AA$. Density is contoured at $1.5 \sigma$ above the mean electron density value. Model-phased anomalous difference density is shown in green, contoured at $10 \sigma$ above the mean electron density value. This figure was generated in $P y M O L$ (Schroedinger).

of $1 \mu \mathrm{l}$ human insulin (Sigma I2643) at $20 \mathrm{mg} \mathrm{ml}^{-1}$ concentration was mixed with $1 \mu \mathrm{l}$ of the reservoir solution. The reservoir solution was composed of $450 \mathrm{mM} \mathrm{Na} \mathrm{NPO}_{4}$ and $10 \mathrm{~m} M$ EDTA at $\mathrm{pH}=10.4$. The crystals were grown within a day of crystallization setup. A slurry of $\sim 15 \mu \mathrm{m}^{3}$ insulin microcrystals were harvested on a $700 \mu$ m-diameter micromesh loop with $10 \mu \mathrm{m}$ openings (Mitegen) and cooled directly in the cryostream. The mesh and collect workflow (Zander et al., 2015) was used to collect 228 partial datasets of $100 \times 0.1^{\circ}$ oscillations, with the beam attenuated to $3.5 \times 10^{11}$ photons $\mathrm{s}^{-1}$ with $40 \mathrm{~ms}$ exposures. Data were indexed and integrated in $X D S$ (Kabsch, 2010) from within GrenADES (Monaco et al., 2013). Partial datasets were grouped with CODGAS (Zander et al., 2016) and the merging statistics of the best group (containing 142 datasets) are shown in Table 2.

\section{Conclusions}

ID23-2 is a fixed-energy energy microcrystallography beamline dedicated to macromolecular crystallography with over 1310 PDB depositions, 1264 publications and 14 patents attributed to it. Recently, the beamline was almost completely rebuilt, dramatically improving the beamline capabilities. Taken together with the ESRF-EBS upgrade, this beamline offers unique capabilities which will enable future advances in structural biology.

\section{Acknowledgements}

The authors would like to acknowledge members of the ESRF-EMBL Joint Structural Biology Group (JSBG) and other ESRF support groups for all their help in this project. We would also like to thank Montserrat Soler Lopez in particular for crystallization. The authors gratefully acknowledge the support of the EMBL Grenoble as part of longstanding collaboration with the Synchrotron Crystallography 
Team led by Andrew McCarthy and the Instrumentation Team for their constant support in maintaining and developing the MD3Up diffractometer as well as the FLEX-HCD sample changer.

\section{References}

Aragão, D., Aishima, J., Cherukuvada, H., Clarken, R., Clift, M., Cowieson, N. P., Ericsson, D. J., Gee, C. L., Macedo, S., Mudie, N., Panjikar, S., Price, J. R., Riboldi-Tunnicliffe, A., Rostan, R., Williamson, R. \& Caradoc-Davies, T. T. (2018). J. Synchrotron Rad. 25, 885-891.

Axford, D., Ji, X., Stuart, D. I. \& Sutton, G. (2014). Acta Cryst. D70, 1435-1441.

Berman, H. M., Westbrook, J., Feng, Z., Gilliland, G., Bhat, T. N., Weissig, H., Shindyalov, I. N. \& Bourne, P. E. (2000). Nucleic Acids Res. 28, 235-242.

Beyerlein, K. R., Dierksmeyer, D., Mariani, V., Kuhn, M., Sarrou, I., Ottaviano, A., Awel, S., Knoska, J., Fuglerud, S., Jönsson, O., Stern, S., Wiedorn, M. O., Yefanov, O., Adriano, L., Bean, R., Burkhardt, A., Fischer, P., Heymann, M., Horke, D. A., Jungnickel, K. E. J., Kovaleva, E., Lorbeer, O., Metz, M., Meyer, J., Morgan, A., Pande, K., Panneerselvam, S., Seuring, C., Tolstikova, A., Lieske, J., Aplin, S., Roessle, M., White, T. A., Chapman, H. N., Meents, A. \& Oberthuer, D. (2017). IUCrJ, 4, 769-777.

Bowler, M. W., Guijarro, M., Petitdemange, S., Baker, I., Svensson, O., Burghammer, M., Mueller-Dieckmann, C., Gordon, E. J., Flot, D., McSweeney, S. M. \& Leonard, G. A. (2010). Acta Cryst. D66, 855-864.

Brockhauser, S., Svensson, O., Bowler, M. W., Nanao, M., Gordon, E., Leal, R. M. F., Popov, A., Gerring, M., McCarthy, A. A. \& Gotz, A. (2012). Acta Cryst. D68, 975-984.

Cipriani, F., Felisaz, F., Lavault, B., Brockhauser, S., Ravelli, R., Launer, L., Leonard, G. \& Renier, M. (2007). AIP Conf. Proc. 879, 1928-1931.

Cowan, J. A. \& Nave, C. (2008). J. Synchrotron Rad. 15, 458-462.

Cusack, S., Belrhali, H., Bram, A., Burghammer, M., Perrakis, A. \& Riekel, C. (1998). Nat. Struct. Mol. Biol. 5, 634-637.

Delagenière, S., Brenchereau, P., Launer, L., Ashton, A. W., Leal, R., Veyrier, S., Gabadinho, J., Gordon, E. J., Jones, S. D., Levik, K. E., McSweeney, S. M., Monaco, S., Nanao, M., Spruce, D., Svensson, O., Walsh, M. A. \& Leonard, G. A. (2011). Bioinformatics, 27, 31863192.

Dickerson, J. L., McCubbin, P. T. N. \& Garman, E. F. (2020). J. Appl. Cryst. 53, 549-560.

Duran, D., Couster, S. L., Desjardins, K., Delmotte, A., Fox, G., Meijers, R., Moreno, T., Savko, M. \& Shepard, W. (2013). J. Phys. Conf. Ser. 425, 012005.

Emsley, P., Lohkamp, B., Scott, W. G. \& Cowtan, K. (2010). Acta Cryst. D66, 486-501.

Evans, G., Alianelli, L., Burt, M., Wagner, A. \& Sawhney, K. J. S. (2007). AIP Conf. Proc. 879, 836-839.

Flot, D., Mairs, T., Giraud, T., Guijarro, M., Lesourd, M., Rey, V., van Brussel, D., Morawe, C., Borel, C., Hignette, O., Chavanne, J., Nurizzo, D., McSweeney, S. \& Mitchell, E. (2010). J. Synchrotron Rad. 17, 107-118.

Foos, N., Cianci, M. \& Nanao, M. H. (2019). Acta Cryst. D75, 200-210.

Gati, C., Bourenkov, G., Klinge, M., Rehders, D., Stellato, F., Oberthür, D., Yefanov, O., Sommer, B. P., Mogk, S., Duszenko, M., Betzel, C., Schneider, T. R., Chapman, H. N. \& Redecke, L. (2014). IUCrJ, 1, 87-94.

Gu, D.-H., Eo, C., Hwangbo, S.-A., Ha, S.-C., Kim, J. H., Kim, H., Lee, C.-S., Seo, I. D., Yun, Y. D., Lee, W., Choi, H., Kim, J., Lim, J., Rah, S., Kim, J.-S., Lee, J.-O., Kim, Y.-G. \& Park, S.-Y. (2021). J. Synchrotron Rad. 28, 1210-1215.

Guijarro, M., Beteva, A., Coutinho, T., Dominguez, M.-C., Guilloud, C., Homs, A., Meyer, J., Michel, V., Papillon, E., Perez, M. \&
Petitdemange, S. (2018). Proceedings of the 16th International Conference on Accelerator and Large Experimental Physics Control Systems (ICALEPCS2017), 8-13 October 2017, Barcelona, Spain, pp. 1060-1066. WEBPL05.

Hirata, K., Ueno, G., Nisawa, A., Kawano, Y., Hikima, T., Shimizu, N., Kumasaka, T., Yumoto, H., Tanaka, T., Takahashi, S., Takeshita, K., Ohashi, H., Goto, S., Kitamura, H., Yamamoto, M., Garrett, R., Gentle, I., Nugent, K. \& Wilkins, S. (2010). AIP Conf. Proc. 1234, 901-904.

Janvier, N., Clement, J. M., Farjado, P. \& Cuni, G. (2013). Proceedings of the 14th International Conference on Accelerator and Large Experimental Physics Control Systems (ICALEPCS2013), 6-11 October 2013, San Francisco, CA, USA, pp. 766-769. TUPPC081.

Jumper, J., Evans, R., Pritzel, A., Green, T., Figurnov, M., Ronneberger, O., Tunyasuvunakool, K., Bates, R., Žídek, A., Potapenko, A., Bridgland, A., Meyer, C., Kohl, S. A. A., Ballard, A. J., Cowie, A., Romera-Paredes, B., Nikolov, S., Jain, R., Adler, J., Back, T., Petersen, S., Reiman, D., Clancy, E., Zielinski, M., Steinegger, M., Pacholska, M., Berghammer, T., Bodenstein, S., Silver, D., Vinyals, O., Senior, A. W., Kavukcuoglu, K., Kohli, P. \& Hassabis, D. (2021). Nature, 596, 583-589.

Kabsch, W. (2010). Acta Cryst. D66, 125-132.

Karplus, P. A. \& Diederichs, K. (2012). Science, 336, 1030-1033.

Krug, M., Weiss, M. S., Heinemann, U. \& Mueller, U. (2012). J. Appl. Cryst. 45, 568-572.

Liu, Q., Liu, Q. \& Hendrickson, W. A. (2013). Acta Cryst. D69, 13141332.

Logan, D. T., Appio, R., Fredslund, F., Haase, D., Martinez-Casado, F. J., Nan, J., Nardella, A., Norén, K., Sigfridsson, K. G. V., Thomas, D., Unge, J., Balmes, O., Carlson, S., Ursby, T. \& Thunnissen, M. M. G. M. (2015). Eur. Phys. J. Plus, 130, 49.

McCarthy, A. A., Barrett, R., Beteva, A., Caserotto, H., Dobias, F., Felisaz, F., Giraud, T., Guijarro, M., Janocha, R., Khadrouche, A., Lentini, M., Leonard, G. A., Lopez Marrero, M., Malbet-Monaco, S., McSweeney, S., Nurizzo, D., Papp, G., Rossi, C., Sinoir, J., Sorez, C., Surr, J., Svensson, O., Zander, U., Cipriani, F., Theveneau, P. \& Mueller-Dieckmann, C. (2018). J. Synchrotron Rad. 25, 1249-1260.

McCoy, A. J., Grosse-Kunstleve, R. W., Adams, P. D., Winn, M. D., Storoni, L. C. \& Read, R. J. (2007). J. Appl. Cryst. 40, 658-674.

McGill, K. J., Asadi, M., Karakasheva, M. T., Andrews, L. C. \& Bernstein, H. J. (2014). J. Appl. Cryst. 47, 360-364.

Monaco, S., Gordon, E., Bowler, M. W., Delagenière, S., Guijarro, M., Spruce, D., Svensson, O., McSweeney, S. M., McCarthy, A. A., Leonard, G. \& Nanao, M. H. (2013). J. Appl. Cryst. 46, 804-810.

Monteiro, D. C. F., von Stetten, D., Stohrer, C., Sans, M., Pearson, A. R., Santoni, G., van der Linden, P. \& Trebbin, M. (2020). IUCrJ, 7, 207-219.

Murshudov, G. N., Skubák, P., Lebedev, A. A., Pannu, N. S., Steiner, R. A., Nicholls, R. A., Winn, M. D., Long, F. \& Vagin, A. A. (2011). Acta Cryst. D67, 355-367.

Nogly, P., James, D., Wang, D., White, T. A., Zatsepin, N., Shilova, A., Nelson, G., Liu, H., Johansson, L., Heymann, M., Jaeger, K., Metz, M., Wickstrand, C., Wu, W., Båth, P., Berntsen, P., Oberthuer, D., Panneels, V., Cherezov, V., Chapman, H., Schertler, G., Neutze, R., Spence, J., Moraes, I., Burghammer, M., Standfuss, J. \& Weierstall, U. (2015). IUCrJ 2, 168-176.

Nave, C. \& Hill, M. A. (2005). J. Synchrotron Rad. 12, 299-303.

Nurizzo, D., Mairs, T., Guijarro, M., Rey, V., Meyer, J., Fajardo, P., Chavanne, J., Biasci, J.-C., McSweeney, S. \& Mitchell, E. (2006). J. Synchrotron Rad. 13, 227-238.

Oscarsson, M., Beteva, A., Flot, D., Gordon, E., Guijarro, M., Leonard, G., McSweeney, S., Monaco, S., Mueller-Dieckmann, C., Nanao, M., Nurizzo, D., Popov, A., von Stetten, D., Svensson, O., Rey-Bakaikoa, V., Chado, I., Chavas, L., Gadea, L., Gourhant, P., Isabet, T., Legrand, P., Savko, M., Sirigu, S., Shepard, W., Thompson, A., Mueller, U., Nan, J., Eguiraun, M., Bolmsten, F., Nardella, A., Milàn-Otero, A., Thunnissen, M., Hellmig, M., Kastner, A., Schmuckermaier, L., Gerlach, M., Feiler, C., Weiss, 
M. S., Bowler, M. W., Gobbo, A., Papp, G., Sinoir, J., McCarthy, A., Karpics, I., Nikolova, M., Bourenkov, G., Schneider, T., Andreu, J., Cuní, G., Juanhuix, J., Boer, R., Fogh, R., Keller, P., Flensburg, C., Paciorek, W., Vonrhein, C., Bricogne, G. \& de Sanctis, D. (2019). J. Synchrotron Rad. 26, 393-405.

Oskarsson, M., Beteva, A., Bolmsten, F., De Sanctis, D., Eguiraun, M., Guijarro, M., Leonard, G., Milan-Otero, A., Nan, J. \& Thunnissen, M. (2018). Proceedings of the 16th International Conference on Accelerator and Large Experimental Control Systems (ICALEPCS2017), 8-13 October 2017, Barcelona, Spain, pp. 180-185. TUBPL05.

Owen, R. L., Holton, J. M., Schulze-Briese, C. \& Garman, E. F. (2009). J. Synchrotron Rad. 16, 143-151.

Pannu, N. S., Waterreus, W.-J., Skubák, P., Sikharulidze, I., Abrahams, J. P. \& de Graaff, R. A. G. (2011). Acta Cryst. D67, 331-337.

Perrakis, A., Cipriani, F., Castagna, J.-C., Claustre, L., Burghammer, M., Riekel, C. \& Cusack, S. (1999). Acta Cryst. D55, 1765-1770.

Petitdemange, S., Claustre, L., Homs, A., Regojo, R. H., Papillon, E., Langlois, F., Mant, G. R. \& Noureddine, A. (2014). Proceedings of the 16th International Conference on Accelerator and Large Experimental Physics Control Systems (ICALEPCS2017), 8-13 October 2017, Barcelona, Spain, pp. 886-890. TUPHA194.

Raimondi, P. (2016). Synchrotron Radiat. News. 29(6), 8-15.

Sanishvili, R., Yoder, D. W., Pothineni, S. B., Rosenbaum, G., Xu, S., Vogt, S., Stepanov, S., Makarov, O. A., Corcoran, S., Benn, R., Nagarajan, V., Smith, J. L. \& Fischetti, R. F. (2011). Proc. Natl Acad. Sci. USA, 108, 6127-6132.

Santoni, G., Zander, U., Mueller-Dieckmann, C., Leonard, G. \& Popov, A. (2017). J. Appl. Cryst. 50, 1844-1851.

Schmidt, M. (2013). Adv. Condens. Matter Phys. 2013, e167276.

Schneider, D. K., Shi, W., Andi, B., Jakoncic, J., Gao, Y., Bhogadi, D. K., Myers, S. F., Martins, B., Skinner, J. M., Aishima, J., Qian, K., Bernstein, H. J., Lazo, E. O., Langdon, T., Lara, J., Shea-McCarthy, G., Idir, M., Huang, L., Chubar, O., Sweet, R. M., Berman, L. E., McSweeney, S. \& Fuchs, M. R. (2021). J. Synchrotron Rad. 28, 650665 .
Sheldrick, G. M. (2010). Acta Cryst. D66, 479-485.

Stellato, F., Oberthür, D., Liang, M., Bean, R., Gati, C., Yefanov, O., Barty, A., Burkhardt, A., Fischer, P., Galli, L., Kirian, R. A., Meyer, J., Panneerselvam, S., Yoon, C. H., Chervinskii, F., Speller, E., White, T. A., Betzel, C., Meents, A. \& Chapman, H. N. (2014). IUCrJ 1, 204-212.

Stetten, D. von, Carpentier, P., Flot, D., Beteva, A., Caserotto, H., Dobias, F., Guijarro, M., Giraud, T., Lentini, M., McSweeney, S., Royant, A., Petitdemange, S., Sinoir, J., Surr, J., Svensson, O., Theveneau, P., Leonard, G. A. \& Mueller-Dieckmann, C. (2020). J. Synchrotron Rad. 27, 844-851.

Storm, S. L. S., Crawshaw, A. D., Devenish, N. E., Bolton, R., Hall, D. R., Tews, I. \& Evans, G. (2020). IUCrJ, 7, 129-135.

Thorn, A. \& Sheldrick, G. M. (2011). J. Appl. Cryst. 44, 1285-1287.

Totir, M., Echols, N., Nanao, M., Gee, C. L., Moskaleva, A., Gradia, S., Iavarone, A. T., Berger, J. M., May, A. P., Zubieta, C. \& Alber, T. (2012). PLoS One, 7, e32498.

Vonrhein, C., Flensburg, C., Keller, P., Sharff, A., Smart, O., Paciorek, W., Womack, T. \& Bricogne, G. (2011). Acta Cryst. D67, 293-302.

Wang, D., Weierstall, U., Pollack, L. \& Spence, J. (2014). J. Synchrotron Rad. 21, 1364-1366.

Welch, B. L. (1947). Biometrika, 34, 28-35.

Winter, G., Waterman, D. G., Parkhurst, J. M., Brewster, A. S., Gildea, R. J., Gerstel, M., Fuentes-Montero, L., Vollmar, M., MichelsClark, T., Young, I. D., Sauter, N. K. \& Evans, G. (2018). Acta Cryst. D74, 85-97.

Wojdyr, M. (2017). J. Open Source Softw. 2, 350.

Yoder, D. W., Sanishvili, R., Vogt, S., Xu, S., Makarov, O., Benn, R., Corcoran, S., Fischetti, R. F., Garrett, R., Gentle, I., Nugent, K. \& Wilkins, S. (2010). AIP Conf. Proc. 1234, 419-422.

Zander, U., Bourenkov, G., Popov, A. N., de Sanctis, D., Svensson, O., McCarthy, A. A., Round, E., Gordeliy, V., Mueller-Dieckmann, C. \& Leonard, G. A. (2015). Acta Cryst. D71, 2328-2343.

Zander, U., Cianci, M., Foos, N., Silva, C. S., Mazzei, L., Zubieta, C., de Maria, A. \& Nanao, M. H. (2016). Acta Cryst. D72, 1026-1035. 